\title{
AS AULAS DE CIÊNCIAS NA VISÃO DE ALUNOS E PROFESSORES DA REDE PÚBLICA E PRIVADA DE ARARAS
}

SCIENCE CLASSES IN THE VIEW OF STUDENTS AND TEACHERS OF THE PUBLIC AND PRIVATE EDUCATIONAL NETWORK OF ARARAS

\section{SILVA, Thainá Verena da ${ }^{1}$; CORTEZ, Raquel Cristina ${ }^{2}$ \\ Centro Universitário Hermínio Ometto - UNIARARAS, Araras, SP.; ${ }^{1 D i s c e n t e ; ~}{ }^{2}$ Orientador. thainaverena@gmail.com}

RESUMO. As aulas de Ciências podem ser diversificadas, com diferentes estratégias de ensino, porém muitas vezes isso não acontece nas escolas, por diferentes motivos. Esta pesquisa teve como objetivo entender como alunos do Ensino Fundamental II julgam ser as aulas de Ciências, comparando com as respostas de seus respectivos professores, além de identificar possíveis sugestões de melhorias no processo de ensino-aprendizagem. A pesquisa foi realizada com questionários respondidos por alunos e professores de uma escola pública e outra particular. As respostas foram analisadas e discutidas de acordo com a bibliografia, o que permitiu algumas comparações e propostas de melhorias. Os achados da pesquisa indicaram que os alunos e professores reconhecem e aprovam a diversificação nas aulas de Ciências como fator para torna-las mais interessantes e auxiliar na construção do conhecimento.

Palavras-chave: Ensino Fundamental; Ciências; estratégias.

ABSTRACT. Science classes can be diverse, with different teaching strategies, but often this does not happen in schools, for different reasons. This research had as objective to understand how students of Middle School judge to be the classes of Sciences, comparing with the responses of their respective teachers, as well as identifying possible suggestions for improvements in the teaching-learning process. The research was carried out with questionnaires answered by students and teachers of a public and private school. Responses were analyzed and discussed according to the bibliography, which allowed for some comparisons and proposals for improvements. The research findings indicated that students and teachers recognize and approve a diversification in science classes as a factor to make them more interesting and ancillary in the construction of knowledge.

Keywords: Middle School; Sciences; strategies.

\section{INTRODUÇÃO}

Desenvolver aulas de Ciências que atraiam a atenção dos discentes é um grande desafio, especialmente por ser uma disciplina cercada de termos científicos e conceitos. Assim, o que se encontra em muitas escolas são aulas monótonas, sem situações práticas que remetam o conteúdo estudado ao dia-dia do aluno.

Os PCN (Parâmetros Curriculares Nacionais) de Ciências Naturais enfatiza, ao descrever um breve histórico sobre o ensino dessa disciplina, que muitas práticas ainda são baseadas apenas na transmissão de informações, usando apenas o livro didático e a transcrição na lousa (BRASIL, 1998). 
Segundo Ramos e Rosa (2008), os professores apresentam dificuldades para a realização de atividades experimentais e de estratégias inovadoras e, dentre os principais motivos citados por eles estão a escassez de material, a falta de um espaço adequado e ainda a falta de preparo dos próprios professores para poder lidar com esse tipo de situação.

Durante um estudo sobre o professor "ideal" ao professor possível de Ciências, Carrijo (2003) enfatiza que o docente deve levar o ensino para fora da sala de aula, explorando recursos naturais e trazer a dinâmica do mundo para dentro da sala (CARRIJO, 2003, p.76).

O objetivo deste trabalho foi compreender a maneira como os alunos de duas salas do Ensino Fundamental II de duas escolas (uma sendo pública e outra particular) julgam ser as aulas de Ciências, além de analisar como elas acontecem de acordo com as respostas dos professores e busca-se ainda identificar possíveis melhorias que podem ser feitas a fim de contribuir no processo de ensino-aprendizagem.

\section{METODOLOGIA}

Este trabalho foi realizado através de uma pesquisa de campo, descrita por Marconi e Lakatos como uma técnica na qual se tem o "objetivo de conseguir informações e/ou conhecimentos acerca de um problema, para o qual se procura uma resposta, ou de uma hipótese, que se queira comprovar, ou, ainda, descobrir novos fenômenos ou as relações entre eles" (MARCONI e LAKATOS, 2003).

Este trabalho foi realizado em duas escolas localizadas na cidade de Araras/SP, sendo uma delas pública e a outra particular. Após contato com os diretores de cada uma, foi assinada a "Declaração de Consentimento para uso da escola", permitindo então que a pesquisa pudesse ser iniciada.

Após o consentimento da direção, a pesquisadora foi autorizada a entrar nas salas de aula onde estavam os possíveis sujeitos. Para explicar como aconteceria a pesquisa e a finalidade desta, foram lidos os termos: "Termo de Assentimento do Menor" e "Termo de Consentimento Livre e Esclarecido", a fim de esclarecer eventuais dúvidas a respeito da pesquisa e deixá-los livres a decidir ou não participar. A professora da escola pública, bem como o professor da escola particular também assinou o "Termo de Consentimento Livre e Esclarecido".

Após a explicação, todos os alunos da sala quiseram levar os termos para os responsáveis assinarem e deveriam trazer com as respectivas assinaturas na data combinada pela pesquisadora.

De acordo com Marconi e Lakatos, "em média, os questionários expedidos pelo pesquisador alcançam 25\% de devolução" (MARCONI e LAKATOS, 2003).

$\mathrm{Na}$ data estipulada, a pesquisadora retornou nas duas escolas e recolheu os termos dos alunos que assinaram o "Termo de Assentimento do Menor" e dos pais que assinaram o "Termo de Consentimento Livre e Esclarecido".

Assim, foi entregue para cada aluno um questionário contendo três questões, sendo a primeira contendo uma parte fechada e outra aberta, a segunda fechada e a terceira aberta, com o objetivo de analisar o que pensam a respeito das aulas de Ciências. Para os professores foi entregue um questionário contendo cinco questões abertas e duas fechadas, com o objetivo de conhecê-los e entender a maneira como trabalham as atividades nas aulas de Ciências.

O questionário é um instrumento para coleta de dados formado por questões previamente elaboradas com a finalidade de obter respostas dos sujeitos (CHIZZOTTI, 2003).

Enquanto o questionário formado por questões abertas permite ao sujeito responder 
livremente usando sua própria linguagem e opiniões, as questões fechadas dos questionários são mais objetivas, facilitando o trabalho do pesquisador, apesar de tolher um pouco a liberdade nas respostas (LAKATOS, 2003).

Durante a aplicação do questionário a pesquisadora leu os enunciados e orientou os alunos com relações às dúvidas apresentadas referentes às questões. Vale ressaltar que tanto os alunos que participaram, quanto os professores, foram de maneira voluntária.

Este trabalho foi aprovado pelo Comitê de Ética em Pesquisa de Mérito Científico Uniararas com o parecer de número CAAE 60787316.7.0000.5385.

\section{RESULTADOS E DISCUSSÃO}

Participaram dessa pesquisa 10 alunos da escola pública e 9 alunos da escola particular, todos do $6^{\circ}$ ano do Ensino Fundamental.

Após a aplicação da pesquisa, iniciou-se o trabalho de leitura dos dados para elaboração dos resultados. Para análise das questões abertas foram formuladas categorias de acordo com as respostas obtidas no questionário.

A primeira questão do questionário dos alunos, "Você acha importante estudar Ciências na escola?", conforme resultados obtidos, 100\% dos alunos da escola pública assinalaram "Sim", 88,9\% dos alunos da escola particular assinalaram "Sim" e 11,1\% assinalaram "Não".

Ainda na primeira questão, eles deveriam justificar a resposta assinalada, então foi perguntado "Por quê?" e entre os que assinalaram "Sim", as respostas foram agrupadas em 3 categorias a seguir: "Importante para formar cientistas", "Importante para aprender sobre o corpo e meio ambiente", "Útil no cotidiano dos alunos", conforme mostra a Tabela 1.

Tabela 1- Respostas dos alunos na questão 1, sobre porque é importante estudar Ciências

\begin{tabular}{ccc} 
& Pública & Particular \\
\hline $\begin{array}{c}\text { Importante para formar } \\
\text { cientistas }\end{array}$ & $30 \%$ & $0 \%$ \\
$\begin{array}{c}\text { Importante para aprender sobre } \\
\text { o corpo e meio ambiente }\end{array}$ & $30 \%$ & $44,45 \%$ \\
Útil no cotidiano dos alunos & $40 \%$ & $44,45 \%$ \\
\hline
\end{tabular}

Somente um $(11,1 \%)$ dos alunos da escola particular assinalou a resposta "Não", e justificou que não considera importante ter aulas de Ciências, pois não considera útil no dia a dia, sendo que muitas coisas aprendidas durante as aulas não são utilizadas depois.

Os dados vêm corroborar o que Brasil (1999) indica quando destaca para a área das Ciências assuntos relacionados à Saúde e Meio Ambiente, sendo que nessa fase os alunos demostram grande interesse por seu próprio corpo e saúde. A maioria também demostrou entender que a disciplina de Ciências contribui de forma significativa para a produção e desenvolvimento do conhecimento e que se motivam ou não em função de temas que lhes despertem mais interesse por serem mais próximos, o que fortalece a importância de uma aprendizagem significativa, ou seja, dentro de um contexto conhecido do aluno (SANTOS et. al. 2011).

Na segunda questão, "Marque um X nas atividades que você realiza ou realizou nas 
aulas de Ciências durante esse ano", o objetivo era entender como ocorreram as aulas, quais estratégias de ensino haviam sido aplicadas pelo professor, além de comparar se houve diferença no uso de estratégias utilizadas em aula entre a escola pública e particular. A questão trazia sete diferentes estratégias para os alunos assinalarem e a seguir têm-se os dados obtidos segundo cada estratégia.

Para a estratégia "Passeios ou visitas a zoológicos, museus, parques, etc" nenhum dos dez alunos $(0 \%)$ da escola pública assinalou indicando que realiza ou que tenha realizado as estratégias elencadas, e todos os nove alunos (100\%) da escola particular assinalaram. $\mathrm{Na}$ segunda estratégia "Experimentos em laboratório" nenhum aluno da escola pública e particular assinalou, o que indica a ausência de atividades em laboratórios.

A próxima estratégia era "Experiências em sala de aula ou no pátio da escola" e todos os dez alunos (100\%) da escola pública assinalaram, já na escola particular oito alunos $(88,9 \%)$ assinalaram e apenas um $(11,1 \%)$ deixou em branco. Para "Jogos, teatros e/ou dinâmicas", os dez alunos (100\%) da escola pública assinalaram e nenhum aluno $(0 \%)$ da escola particular assinalou.

Os dados apontam para a dificuldade de implementação de atividades fora da escola. Embora as visitas a espaços naturais ou a ambientes de preservação e conservação sejam importantes para a aprendizagem significativa em Ciências, nem sempre esse tipo de estratégia é utilizada pelas escolas, especialmente as públicas. Estudos mostram que entre as principais dificuldades para os trabalhos de campo estão as condições logísticas, materiais e financeiras (DOURADO, 2006).

Por outro lado, os dados mostraram a boa utilização de outros espaços que podem proporcionar ricas atividades possibilitando aos alunos a compreensão de que "fenômenos e processos naturais estão presentes no ambiente como um todo, não apenas no que ingenuamente é chamado de natureza" (BRASIL, 1998, p.126).

O pátio da escola, praças e jardins próximos ao local de estudos dos alunos podem possibilitar ricos trabalhos de campo e possibilitam ao aluno a percepção dos processos naturais integrados ao ambiente como um todo e não apenas no espaço chamado por muitos de "natureza" (BRASIL, 1998).

Em "Pesquisas, leituras e/ou uso de softwares em laboratório de informática" nenhum aluno $(0 \%)$ da escola pública assinalou e sete alunos $(77,78 \%)$ da escola particular assinalaram e dois $(22,22 \%)$ deixaram em branco. Para "Debates sobre assuntos diversos" todos os dez alunos (100\%) da escola pública assinalaram, seis alunos $(66,67 \%)$ da escola particular assinalaram e três $(33,33 \%)$ deixaram em branco. A última estratégia era "Uso de livros didáticos, apostilas ou textos impressos em sala de aula" e tanto os dez alunos (100\%) da escola pública, quanto os nove $(100 \%)$ da escola particular assinalaram.

Os dados apontam que os livros didáticos, apostilas, textos xerocados ainda predominam como uma das principais ferramentas de trabalho em sala de aula. $\mathrm{O}$ uso da internet para pesquisas, softwares interativos poderiam proporcionar aos alunos uma riqueza de informações, tornando as aulas mais atrativas e a aprendizagem dos conteúdos de Ciências mais significativos.

A terceira e última questão era aberta, "O que você pensa que deveria ter em uma aula de Ciências para ser motivadora e ajudar o aluno a aprender melhor?", e as respostas foram agrupadas em 3 categorias: "Ter um laboratório", "Ter saídas a campo" e "Ter aulas mais dinâmicas".

Ao se tratar de motivação, Fita (1999) infere que para melhorar a motivação dos alunos não existem receitas mágicas, mas deve existir criatividade por parte do docente a fim 
de que diferentes estratégias possam ser utilizadas e assim diversificar a maneira como as aulas são abordadas.

Na escola pública, como é possível visualizar na figura abaixo (Figura 1), cinco alunos (50\%) responderam "Ter aulas mais dinâmicas", quatro alunos (40\%) responderam "Ter saídas a campo" e apenas um (10\%) respondeu "Ter um laboratório".

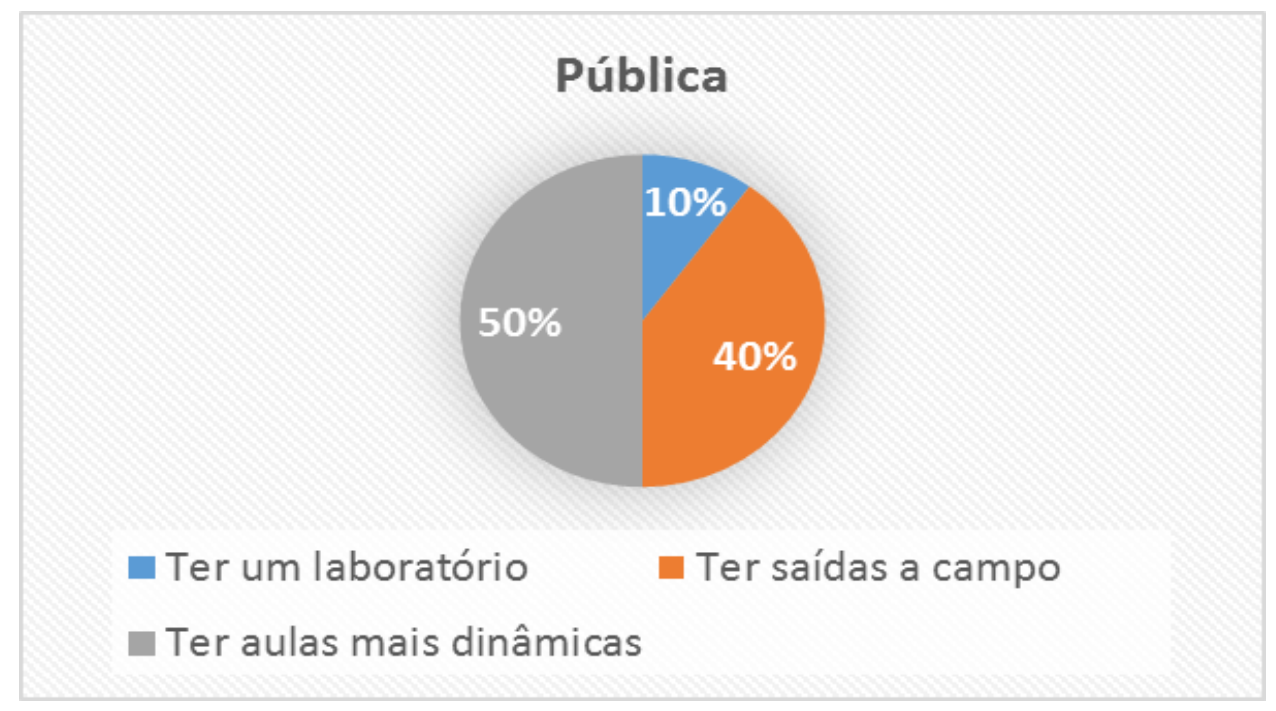

Figura 1 - Porcentagem das respostas na questão três - escola pública.

Na figura a seguir (Figura 2), estão representadas as respostas dos alunos da escola particular, onde quatro alunos (44,45\%) responderam "Ter aulas mais dinâmicas", quatro $(44,45 \%)$ responderam “Ter um laboratório" e apenas um $(11,1 \%)$ "Ter saídas a campo".

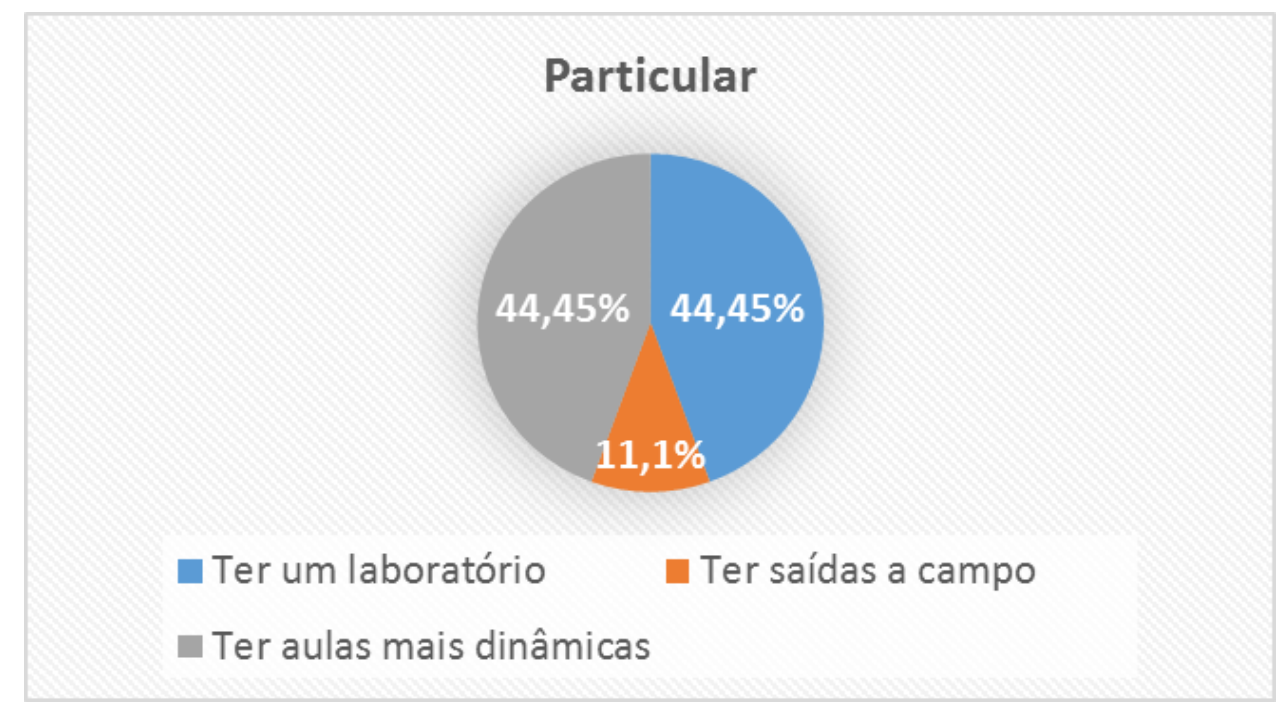

Figura 2 - Porcentagem das respostas na questão três - escola particular

Os dados indicam que tanto alunos da escola pública (50\%) quanto os da particular $(44,45 \%)$ se mostrariam mais motivados com a existência de aulas mais dinâmicas, o que reforça o que descrevem Carvalho e Gil Perez (2003), que o ensino e a aprendizagem em 
Ciências e Biologia devem ultrapassar o "ensino tradicional", em que o conteúdo é transmitido como conhecimento elaborado e com frequentes apresentações expositivas pelo professor.

Percebe-se que os alunos da escola pública relacionam que as aulas de Ciências podem mais motivadoras quando existem saídas a campo. Esse dado pode ser comparado com os achados da questão número dois em que esses alunos indicaram que não participavam de passeios ou visitas a zoológicos, museus, parques e $40 \%$ deles afirmaram que as aulas seriam mais motivadoras se houvessem saídas a campo. O mesmo não foi percebido com os alunos da escola particular, que embora $44,45 \%$ tenham apontado que a utilização de dinâmicas tornariam as aulas de Ciências mais motivadoras, não indicam as saídas a campo na questão número três, pois essa é uma prática comum na escola, dado comprovado na questão número dois em 100\% dos alunos apontaram a existência de saídas para trabalho de campo.

Brasil (1998), aponta como indispensável o desenvolvimento do ensino de Ciências articulado aos trabalhos de campo e as atividades de classe.

Quanto à categoria "Ter um laboratório", pôde-se perceber que esse item é considerado importante para que as aulas sejam mais motivadoras, pois $44,45 \%$ dos alunos da escola particular responderam que gostariam que a escola tivesse um laboratório para realizar experimentos e não reconhecem que essas atividades acontecem na sala de aula ou pátio da escola, conforme apontado na questão número dois.

Já os alunos da escola pública parecem não sentir essa necessidade, já que somente $10 \%$ deles responderam que gostariam de realizar práticas em laboratório. Esse dado pode ser relacionado com a questão número dois em $100 \%$ dos alunos da escola pública indicaram já ter vivenciado experiências em sala de aula ou no pátio da escola, demostrando que ter um laboratório não é condição indispensável para realizar experimentos e tornar as aulas mais motivadoras.

Como destaca Galvão; Lima e Silveira (2009), a falta de recursos e investimento nas escolas públicas é algo indiscutível. Todavia, existem diversas estratégias que podem ser utilizadas no ensino de Ciências que não precisam necessariamente de muitos recursos.

Brasil (1998) destaca que a experimentação pode ser realizada com ou sem a presença de um laboratório na escola, mas ela acontece quando os alunos discutem ideias, manipulam materiais, ou mesmo quando são solicitados a construírem algum experimento.

Almeida (1998) afirma que não são apenas os laboratórios que devem ser utilizados para atividades práticas, mas que a sala de aula e todos os outros espaços dentro da escola podem ser usados para o registro de descoberta dos alunos.

Mesmo em escolas que possuem um laboratório equipado, pode ocorrer do experimento ser trabalhado como uma atividade em que o professor apenas segue um protocolo, faz uma demonstração e o aluno fica como mero observador. Portanto somente ter um laboratório na escola não garante a aprendizagem significativa em Ciências.

Os professores, tanto o da turma da escola pública, quanto da particular, também responderam a um questionário, as quatro primeiras questões tinham por objetivo levantar informações sobre a formação acadêmica e vida profissional de cada um deles. A primeira questão era "Qual a sua formação acadêmica? Você cursou Licenciatura? Em qual instituição de ensino?".

A professora da escola pública respondeu ser formada em Ciências Físicas e Biológicas com habilitação plena em Biológia, declarou ter cursado Licenciatura e a Instituição de ensino é a Fundação Hermínio Ometto (Uniararas). O professor da escola particular respondeu ser formado em Ciências Biológicas, declarou ter cursado Licenciatura, a 
Instituição de ensino é a UFSCAR.

Apesar de os dois professores terem se graduado em diferentes universidades, eles responderam terem cursado Licenciatura. Artigos apontam que, mesmo em cursos que formam de professores, ainda prevalece a visão do docente como transmissor de conteúdos e também abordam a questão do distanciamento entre a formação e o cotidiano escolar e os inúmeros desafios que terá que enfrentar esse docente, muitas vezes sem ter a formação adequada para tal (CUPOLILLO e FONSECA, 2004).

Tal fato tem impulsionado muitas instituições a rever suas metodologias e a investir em capacitações de professores que atuam na Educação Superior.

A segunda questão também se tratava da formação do professor, perguntava: "Há quanto tempo se formou? Há quanto tempo você é professor de Ciências?", as respostas são apresentadas a seguir.

Os dois professores se formaram em anos diferentes, mais precisamente com dezesseis anos de diferença. A professora da escola pública declarou ter se formado no ano de $1998 \mathrm{e}$ atua como professora de Ciências desde 1999, já o professor da escola particular declarou ser ter se formado no ano de 2014 e atua como professor de Ciências desde o ano de 2012, o que nos mostra que ele começou atuar na área enquanto ainda estava cursando Ciências Biológicas.

Já a terceira questão tratava do atual exercício de cada um como professor: "Em quantas escolas você trabalha? Atua na rede pública e/ou privada?". A professora da escola pública respondeu que atua apenas em uma escola, sendo ela da rede pública. O professor da escola particular explicou que já atuou em três escolas da rede pública, mas atualmente leciona apenas na escola particular.

Para finalizar as questões de identificação do professor, a quarta questão dizia: "Cite os principais cursos (curso de formação continuada, especialização, mestrado, doutorado etc.) que você realizou/realiza".

Nesta questão a professora da escola pública respondeu ter feito um curso de formação continuada "Estatuto da criança e do adolescente" e pós graduação em "Administração Educacional". O professor da escola particular respondeu ter feito uma pós graduação em "Microbiologia Aplicada (Mestre)".

Com relação aos cursos de formação continuada, mesmo que de modo diferente, os dois professores afirmaram terem feito. Edwald et. al. (2013), ao falar sobre a formação continuada, comentam sobre a necessidade do professor de renovar os conhecimentos e se atualizar com uma grande velocidade quando se trata de Ciências, visto que constantemente surgem novas descobertas e isso exige adaptação do professor nos desafios do cotidiano escolar.

A partir da quinta questão, os professores responderam perguntas voltadas para a concepção e importância da atividade prática para o professor. Sendo assim a questão de número cinco dizia o seguinte: "Você trabalha ou já trabalhou com algumas dessas estratégias para o ensino de Ciências em suas aulas? Assinale um X em quais já trabalhou".

Tanto a professora da escola pública, quanto o professor da escola particular assinalaram as seguintes estratégias em comum: Estudo do meio; Observação; Experimentação e Uso de textos. Nenhum dos dois professores assinalou "Simulação" e "Debate". Somente a professora da escola pública assinalou "Jogos" e em "Outras" disse ter feito o uso de datashow/vídeos. As estratégias "Uso da informática" e "Uso de laboratório" foram assinaladas somente pelo professor da escola particular, ele declarou em "Outras" ter feito o uso de filmes e resenhas. 
Apesar de a professora da rede pública não ter assinalado a opção "Debate", os alunos $(100 \%)$ em seus questionários responderam que houve. Pode ter acontecido que alguma situação os alunos terem interpretado como um debate e a professora não ter considerado da mesma forma. Altarugio; Diniz e Locatelli (2010), explicam que promover debates durante as aulas oferece oportunidades para que os alunos exponham suas ideias prévias. Outro ponto a ser destacado, é o fato de que realizar debates nas aulas de Ciências não demanda custo, materiais extra, etc.

Ainda em relação a pergunta feita aos professores: "Por qual(is) motivo(s) você trabalha /não trabalha com essas estratégias em suas aulas de Ciências?" e as respostas estão transcritas a seguir.

Professora da rede pública: "Acredito que com essas práticas as aulas se tornam mais interessantes, levam os alunos a elaborar hipóteses, auxilia o desenvolvimento em outras disciplinas (textos). Obs.: Não possuímos laboratório, as aulas são realizadas na própria sala com materiais que a escola possui ou trazidos pelo próprio professor."

Professor da rede particular: "Eu escolho a estratégia de ensino com relação ao perfil de cada sala e como didaticamente uma turma irá melhor assimilar o conteúdo que estou passando".

As respostas se relacionam com as que os professores deram na última questão, que será apresentada a seguir. Mas a observação feita pela professora da escola pública se relaciona com as respostas dadas pelos alunos quando somente $10 \%$ deles descreveram que para que as aulas fossem mais motivadoras precisava-se ter um laboratório. $\mathrm{O}$ restante que não respondeu dessa maneira, provavelmente deve-se ao fato de a professora utilizar o espaço da sala de aula, mesmo sem possuir laboratório na escola, para realizar aulas práticas.

Cabe aqui ressaltar o que Cruz (2008) comenta a respeito, dizendo que a sala de aula pode realmente ser usada na falta de um laboratório, cabendo ao professor adaptar a aula, como o uso de materiais e a montagem do local para realizar as experimentações.

Por fim, a questão de número sete dizia: “Assinale as afirmações de 1 a 6 , por ordem de importância (sendo 1 a mais importante e 6 a de menor importância), segundo sua opinião. Quando você usa atividades práticas, se preocupa em (ler opções):". As opções eram: "Tornar a aula mais interessante", "Despertar a curiosidade do aluno", "Contribuir para que o aluno reformule suas ideias prévias", "Desenvolver no aluno o raciocínio crítico através da capacidade de questionar, refletir, propor hipóteses e interpretar", "Facilitar a aprendizagem da Ciência" e "Relacionar teoria e prática".

No Quadro 1, é possível observar a maneira como cada um dos professores, tanto da escola pública, quanto da escola particular, organizaram suas respostas por ordem de importância.

Quadro 1 - Organização das respostas dos professores.

\begin{tabular}{|l|}
\hline Pública \\
\hline 1.Despertar a curiosidade do aluno e motivá-lo \\
\hline 2. Relacionar teoria e prática \\
\hline $\begin{array}{l}\text { 3. Desenvolver no aluno o raciocínio científico através da capacidade de questionar, refletir, propor hipóteses e } \\
\text { interpretar }\end{array}$ \\
\hline 4. Contribuir para que o aluno reformule suas ideias prévias \\
\hline 5. Tornar a aula mais interessante \\
\hline 6. Facilitar a aprendizagem da Ciência \\
\hline Particular \\
\hline
\end{tabular}




\begin{tabular}{|l|}
\hline $\begin{array}{l}\text { 1. Desenvolver no aluno o raciocínio científico através da capacidade de questionar, refletir, propor hipóteses e } \\
\text { interpretar }\end{array}$ \\
\hline 2. Relacionar teoria e prática \\
\hline 3. Facilitar a aprendizagem da Ciência \\
\hline 4. Contribuir para que o aluno reformule suas ideias prévias \\
\hline 5. Despertar a curiosidade do aluno e motivá-lo \\
\hline 6. Tornar a aula mais interessante \\
\hline
\end{tabular}

Analisando as respostas, é possível observar que os dois professores responderam da mesma maneira apenas para o itens "Relacionar teoria e prática" e "Contribuir para que o aluno reformule suas ideias prévias. Nas respostas dadas pelos professores no item 1 e 6, pode-se inferir que a professora da escola pública esteja mais preocupada em criar situações para que a aprendizagem dos alunos aconteça, enquanto que o professor da escola particular tenha mais focalizado a questão de tornar as aulas e o ensino mais interessantes e, dessa forma, desenvolver nos alunos algumas competências como a capacidade de questionar, de refletir, propor hipóteses e interpretar.

\section{CONCLUSÃO}

Este trabalho teve por objetivo compreender como alunos da rede pública e particular de ensino de Araras julgam ser as aulas de Ciências e identificar possíveis melhorias a fim de contribuir no processo de ensino aprendizagem. Inicialmente foi realizado um levantamento bibliográfico e observou-se que o ensino de Ciências deve ser voltado ao cotidiano do aluno, além de não ser exclusivamente expositivo.

A maioria dos alunos que participou da pesquisa, tanto da escola pública quanto da particular considera importante estudar Ciências, mas nas duas situações sinalizaram que sentiriam maior motivação se as aulas fossem mais dinâmicas, com mais debates, saídas de campo, ou seja, com estratégias diversificadas e com maior participação dos alunos. A escola particular realizou atividades de campo e uso de informática durante as aulas, o que não ocorreu na pública. Teatro, jogos ou dinâmicas foram realizados apenas na escola pública.

Percebem-se diferenças entre as atividades realizadas nas duas escolas, porém apesar de não possuírem laboratório, realizaram atividades no pátio ou na sala, fizeram o uso de debates e de livros didáticos e apostilas.

Para que as aulas de Ciências se tornem mais motivadoras, além de melhorar a infraestrutura das escolas, investir na formação continuada do professor para que possam ser trabalhadas estratégias que permitam ao aluno construir conhecimento e relacioná-los em seu cotidiano, a equipe escolar deve considerar o espaço escolar lugar ideal para o desenvolvimento da verdadeira formação, com o compartilhamento de experiências e discussões dos problemas reais. Portanto, uma ação conjunta de toda gestão escolar pode surtir efeitos positivos tanto nas aulas de Ciências, quanto nas demais aulas e atividades que acontecem no espaço escolar.

\section{REFERÊNCIAS}

ALMEIDA, P. N. de. Educação lúdica. São Paulo: Loyola, 1998.

ALtARUGIO, M. H; DINIZ, M. L; LOCATELLI, S. W. Debate como estratégia em aulas 
de química. Química Nova Escola, vol. 32, nº 1, fev. 2010.

BRASIL. Secretaria de Educação Fundamental. Parâmetros curriculares nacionais: Ciências Naturais / Secretaria de Educação Fundamental. Brasília: MEC / SEF, 1998. 138 p.

CARRIJO, I. L. M. Do Professor "Ideal” (?) de Ciências ao Professor Possível. Araraquara: JM Editora, 1999. p. 122

CARVAlHO, A. M. P. de; Gil-Pérez, D. Formação de Professores de Ciências Tendências e Inovações. 7 ed. São Paulo: Cortez Ed., 2003.

CHIZZOTTI, A. Pesquisas em ciências humanas e sociais. 6. ed. São Paulo: Cortez, 2003.

CRUZ, D. A. da. Atividades prático-experimentais: tendências e perspectivas. UEL, Londrina, p.16, 2008.

CUPOLILLO, A. V.; FONSECA, L. C. de S.; Repensando a formação de professores a partir da epistomologia da complexidade. Rev. Uni. Rural, Sér. Ciências Humanas. Seropédica, RJ, EDUR, v. 26, n. 1-2, p. 01 -04 jan-dez, 2004.

DOURADO, L. Concepções e práticas dos professores de Ciências Naturais relativas à implementação integrada do trabalho laboratorial e do trabalho de campo. Revista Electrónica de Enseñanza de las Ciencias Vol. 5 No 1 (2006).

EDWALD, K. P. et. al. Formação continuada de professores: Ensino de Ciências e a fotografia como estratégia integradora. $1^{\circ}$ Encontro de Ciências em Educação para a Sustentabilidade, p. 8, 2013.

FITA, E. C. O professor e a motivação dos alunos. In: TAPIA, J. A.; FITA, E. C. A motivação em sala de aula: o que é, como se faz. 4. ed. São Paulo: Loyola, 1999. p. 65-135.

GALVÃO, G. F.; LIMA, S. A. L.; SILVEIRA, R. M. C. F. O enfoque Ciência, Tecnologia, Sociedade e Ambiente como estímulo ao desenvolvimento de uma cultura científica e tecnológica. Universidade Tecnológica Federal do Paraná - UTFPR. Programa de PósGraduação em Ensino de Ciência e Tecnologia - PPGECT. I Simpósio Nacional de Ensino de Ciência e Tecnologia - 2009.

MARCONI, M. A.; LAKATOS, E. M. Fundamentos de Metodologia Científica. 5. ed. São Paulo: Atlas 2003.

SANTOS, A. C. et. al. A Importância do Ensino de Ciências na percepção de estudantes de Escolas da Rede Pública Municipal De Criciúma - SC. Revista Univap, São José dos Campos-SP, v. 17, n. 30, dez.2011.

RAMOS, L. B. C.; ROSA, P. R. S. O ensino de ciências: fatores intrínsecos e extrínsecos que limitam a realização de atividades experimentais pelo professor dos anos iniciais do ensino fundamental. Investigações em Ensino de Ciências, Porto Alegre, v. 13, n. 3, p. 299-331, 2008. 